\title{
Design-of-use and design-in-use by customers in differentiating value creation
}

\author{
T. Haraa, ${ }^{a}$, S. Shimada ${ }^{a}$, T. Arai $(1)^{b}$ \\ ${ }^{a}$ RACE(Research into Artifacts, Center for Engineering), The University of Tokyo, Chiba 277-8568, Japan \\ ${ }^{b}$ Department of Mechanical Engineering, Shibaura Institute of technology, Tokyo 135-8548, Japan
}

Customer use processes should be more focused in both products and services for better customer satisfaction. The paper proposes a model of value creation by encouraging two types of customer activities pertaining use processes: design-of-use (configuration design before use) and design-in-use (adaptive design during use). By retrieving and utilizing data on usage generated by customers, different classes of value creation (i.e., provided value, adaptive value, and co-creative value) may work together. The proposed model is exemplified by a study on tourism involving a travel agency, independent travelers, and a community of travelers.

Keywords: Design, Customization, Value creation

\section{Introduction}

The field of design theory has a rich collection of research results that have been taught at educational institutions and has been applied to design practices [1]. Recently, the relationship between 'design' and 'use' has become a core issue in developing approaches regarding user-centered design [2]. This implies a holistic view of design as a process that is tightly coupled to use and that continues during the use of a product. The use phase must be incorporated into the design phase, and as the design has to adapt to users; manufacturers and users must be able to collaborate/cooperate for the design of a product or service [3]. The two phases must overlap, intertwine, and simultaneously change. Moreover, design activities have been placed in a wider complex socio-technical context, where Product Service Systems [4] and service engineering [5] are considered.

A preceding study by the authors [6] argued in favor of continuous value creation by encouraging users' design activities alongside designer's activities. User involvement and user participation in the design of a product is promoted as a way to add value, as it clarifies user requirements and enables design modification by the user (e.g., [7]). The cyclic processes of these two activities are crucial for continuous value creation in participatory design, thus bringing design and use closer to each other. In the preceding study, a basic framework for this was presented and exemplified using tourism products. The reason we focus on tourism is that many hints for manufacturing industries are obtained through the study of sightseeing planning in tourism, where free independent travelers (FITs) plan tours and adapt the plan during its use (i.e., while they are sightseeing).

This paper explores into such issues in more detail by introducing two concepts: the term 'design-in-use' that emphasizes the synthesizing aspect of the use phase and the classifications of value creation models that are currently known to the CIRP community. The rest of this paper is organized as follows. Section 2 reviews previous studies about the design-inuse and value creation models. Section 3 illustrates combination of design processes by the manufacturer, individual customer, and customer community focusing on design-in-use as an enabler of bridging different value creation models. In Section 4, we use tourism in order to exemplify the processes. Section 5 discusses and Section 6 concludes the paper.

\section{Related study}

\subsection{Value creation models}

Ueda et al. proposed three value creation models based on the concept of emergent synthesis [8]: provided value model, adaptive value model, and co-creative value model.

Class I value creation model (provided value)

The value for a provider and a receiver of a product or a service can be specified independently, and the environment can be determined in advance. The model can be described as a closed system. The problem to address is the search for the optimal solution.

Class II value creation model (adaptive value)

The value for a provider and a receiver can be specified, but the environment changes, making it difficult to make a prediction. The model is a system that is open to the environment. The problem to address is the adaptive strategy.

Class III value creation model (co-creative value)

The value for a provider and a receiver cannot be determined independently. The two values interact with each other, and thus, they cannot be separated. The provider enters the system. Besides ascertaining the dynamic environmental constraints, this class has to cope with the iterative determination of the system structure. The problem to address is value co-creation.

Most studies on value co-creation have primarily provided examples of existing products or services even though the concept of co-creation originally attracted attention for the design of new products or services [8].

\subsection{Design-in-use}

We employed the concept of design-in-use as the idea that a variety of use situations can display more design-like characteristics rather than just consuming functions arranged by professional designers. Design-in-use activities of a very diverse set of actors can become realistic sources of innovation and material for other designs. Previously, Henderson and Kyng [9] 
made an important conceptualization of such activities and identified continuing design-in-use and tailorability as key aspects to consider for truly collaborative design. Botero et al. [10] proposed four factors of design-in-use strategies: support the open-ended design process and a flexible agency, provide meaningful access to the available resources, create means for sharing designs, and design for openness and designability.

\section{Design-in-use by customer in differentiating value creation}

First this section describes the engineering processes of a product that require high customer participation. Then a combination of different value creation models is illustrated by encouraging two types of customer activities: design-of-use and design-in-use.

\subsection{Configuration and adaptation by the customer}

Figure 1(a) shows the generic engineering processes of a product, in which the design and production are completely executed by the manufacturer, and the product is used by the customer (i.e., the consumer). Fig. 1(b) illustrates the engineering processes of a product involving high customer participation, which focus on product configuration and adaptation by the customer; full design by the manufacturer is replaced with a preparatory design, with the customer serving as a co-creator. The process shown in Fig. 1(a) is quite similar to the engineering process of sightseeing package tours by travel agencies in the tourism industry, while the process shown in Fig. 1(b) is similar to that of free individual travel used by FITs, with the help of tour planning services. We discuss both processes in a later section.

In this paper, configuration by the customer is referred to as design-of-use, while adaptation by the customer is referred to as design-in-use. Since functions and structures of the product or service may change during design-of-use and design-in-use, it is worth collecting design, usage data, in addition to customer satisfaction data, for a better understanding of the customer.

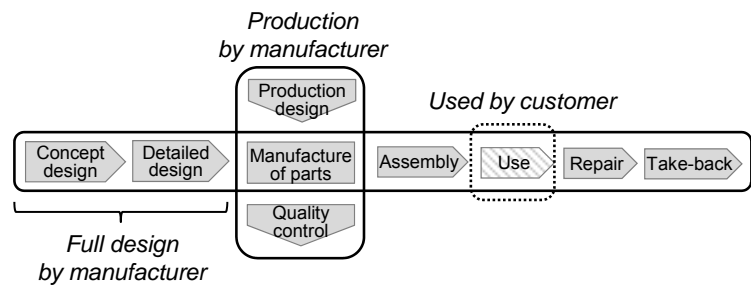

(a) General engineering processes of a product.

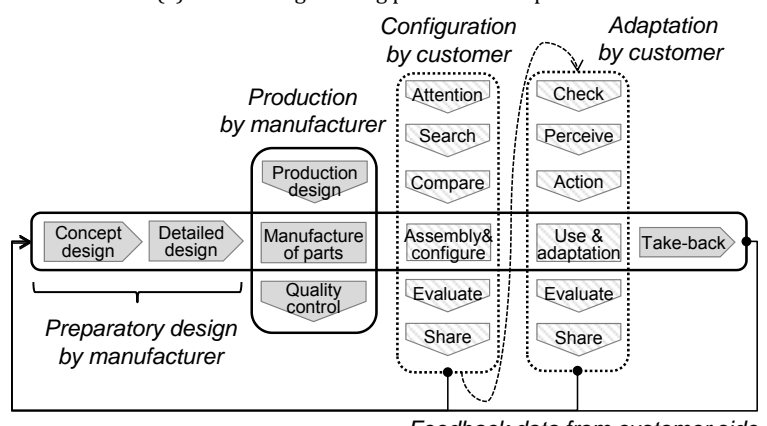

Feedback data from customer side

(b) Engineering processes of a product involving high customer participation

Figure 1 Engineering processes with high customer involvement.

Based on the above, we present design activities by manufacturer, individual customer, and community of customers as shown in Fig. 2, focusing on design-of-use and design-in-use as an enabler of bridging different value creation models. The detail for each value creation model is as follows.

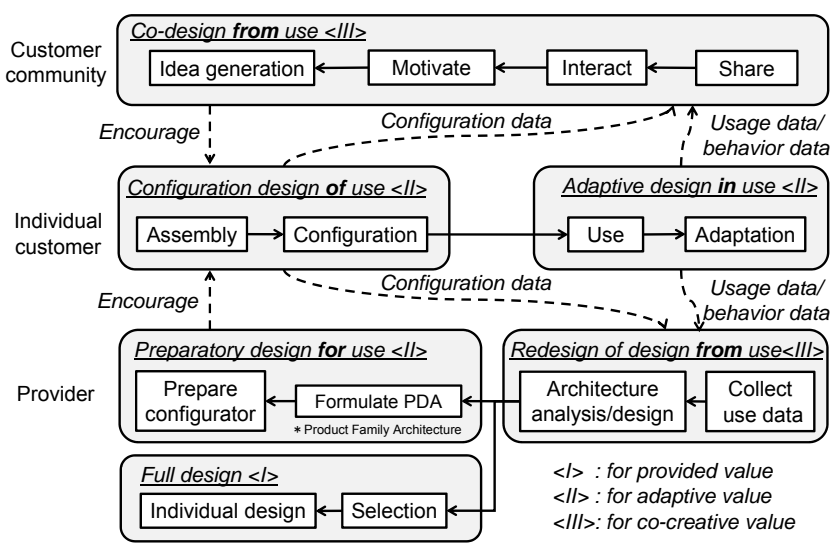

Figure 2 Combination of different value creations involving design-of-use and design-in-use by the customer.

\subsection{Design-of-use and design-in-use for adaptive value (Class II)}

Let the cyclic processes start at 'formulate PFA (Product Family Architecture),' which is done by manufacturer without customer's direct involvement. Tseng anticipated developing a design method for mass customization based on PFA [11]. In this phase, since the manufacturer has not completed designing a product or service, 'formulate PFA' and 'prepare configurator' are regarded as 'preparatory design for use' activities to support 'configuration design of use' by an individual customer. Using the configurator prepared by the manufacturer, the customer assembles and configures the product to meet his/her needs. This entails adaptive value creation based on a certain environment specified in the configuration design process. In contrast, this environment may change during varied use processes. Therefore, design-inuse or adaptive design in use may be undertaken to adapt the product/service to the situated needs.

As described in the section 3.1, collecting use data (a mixture of configuration data, usage data, and behavior data) is worthwhile for better design-from-use. It would be a basic approach for emergent service research such as service science, service engineering, or Product Service Systems, to collect and analyze data on use and/or customer behavior, using technical devices such as GPS logger, RFID tag, IC card, and POS (Point Of Sales) system.

\subsection{Design-from-use for co-creative value (Class III)}

There are two ways of utilizing such accumulated data generated by the customer, so that other stakeholders can effectively undertake design-from-use. The first concerns the manufacturer's internal redesign activity, and the second, sharing the data in the customer community to enable co-design. Both codesign from use in the community and redesign from use at the manufacturer are characterized activities for co-creative value creation. This is because retrieving and analyzing use data enhance continuous learning about the customer for manufacturer, along with co-creation opportunities, planning and implementation.

'Redesign of design from use' with such learning at the manufacturer's end improves the product/service architecture and contributes to 'preparatory design for use' enabling better collaborative customization. Data mining methods, Design or Dependency Structure Matrix (DSM) methods, and other related system analysis techniques can be employed for architecting the system. 
Regarding 'co-design from use', a key factor is to create the means for sharing design knowledge and experiences captured during design-in-use and design-of-use by customers. Individuals, groups, and communities share the knowledge and experiences with peers and social networks. Co-design motivates further (improved) design or planning by each customer.

\subsection{Full design for provided value (Class I)}

The result of architecture design in redesign from use enables the manufacturer to implement transparent customization, which provides predefined products to each customer segment without informing the customer that the product has been customized to their needs. This requires the manufacturer to continuously collect information and make an assessment of the customer's needs in other ways, to create suitable product offerings. Redesign processes based on accumulated use data may provide manufacturers the needed support to retrieve such information about customers.

\section{An illustrative example}

\subsection{Necessity of tour planning for FITs}

Like the preceding study by the authors [6], this paper exemplifies tourism services. The tourism service is a typical service in which a customer's activities are greatly emphasized with design processes similar to those of physical products. Furthermore, one of its characteristics is non-expert design by FITs (e.g., design-of-use). Varied use processes and adaptive planning can be seen while travelling (e.g., design-in-use).

Inbound tourism is especially targeted in this study. A survey conducted in 2009 for inbound tourists visiting Japan revealed that the tourist information center was rated the second in terms of dissatisfaction (28.9\%), followed by difficulty in understanding Japanese $(20.0 \%)$. This data indicates that tour planning support before and/or during tourist stay in Japan would need to be enhanced by a scalable computational approach, so as to ensure better satisfaction for thousands of inbound FITs.

\subsection{Combination of value creation models in tourism}

The following are instances of tourism services corresponding to the value creation models mentioned in the section 2.1.

- Class I provided value creation: sightseeing packaged tour preliminarily designed by a travel agency.

- Class II adaptive value creation: custom-made packaged tour adapted by a travel agency (i.e., provider-driven) and individual tour adapted by FITs with the help of a tour planning service (i.e., customer-driven).

- Class III co-creative value creation: social network service allowing FITs to share knowledge and experiences with each other (e.g., TripAdvisor, EveryTrail, and Facebook).
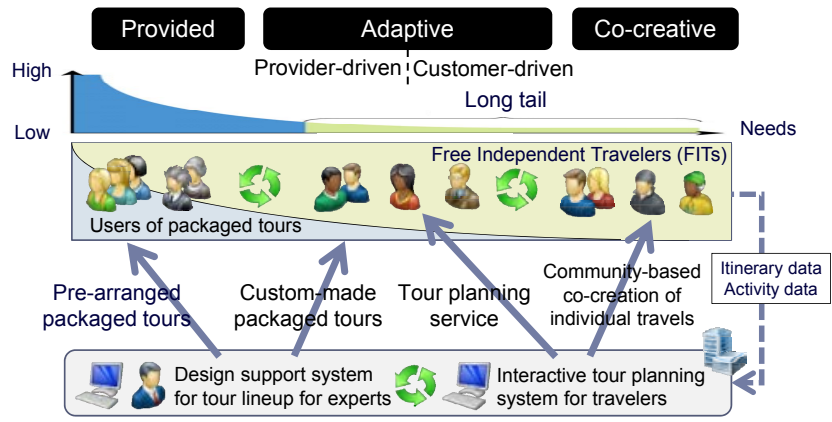

Figure 3 Different value creation models in tourism service (modified from [6]).
Figure 3 shows a schematic illustration of this value creation along with the continuum of volume of travelers' needs, ratio of packaged tour users, and ratio of FITs. In our study, we conducted an analysis of tourist activities in Tokyo by using a GPS logger. This helped us develop two design support systems: design support system for tour lineup for travel agencies (experts) [12] and interactive tour planning system for travelers. Using these systems, an ecosystem in tourism sustained by a travel agency, FITs, and packaged tours users is illustrated in the lower half of Fig.3. A comparison of the two systems is shown in Table 1.

Table 1 Comparison of the developed two systems

\begin{tabular}{|c|c|c|}
\hline System & $\begin{array}{l}\text { Design support system of } \\
\text { tour lineup }\end{array}$ & $\begin{array}{l}\text { Interactive tour planning } \\
\text { system }\end{array}$ \\
\hline User & Travel agencies (experts) & Travelers (non-experts) \\
\hline \multirow{2}{*}{$\begin{array}{l}\text { Support } \\
\text { design }\end{array}$} & Variation design & Configuration design of use \\
\hline & Preparatory design for use & $\begin{array}{l}\text { Adaptive design in use } \\
\text { Co-design from use }\end{array}$ \\
\hline \multirow{2}{*}{$\begin{array}{l}\text { Design } \\
\text { variable }\end{array}$} & Tourist attractions to visit & Tourist attractions to visit \\
\hline & $\begin{array}{l}\text { Staying time at attractions } \\
\text { Functions of tour operation }\end{array}$ & Staying time at attractions \\
\hline Model & Detailed and layered & Simple and intuitive \\
\hline $\begin{array}{l}\text { Number } \\
\text { of tours }\end{array}$ & $\begin{array}{l}\text { Multiple (constraints among } \\
\text { tours are considered) }\end{array}$ & Single \\
\hline \multirow{2}{*}{$\begin{array}{l}\text { Value } \\
\text { creation }\end{array}$} & Provided value creation & Adaptive value creation \\
\hline & $\begin{array}{l}\text { Adaptive value creation } \\
\text { (provider-driven) }\end{array}$ & $\begin{array}{l}\text { (traveler-driven) } \\
\text { Co-creative creation }\end{array}$ \\
\hline
\end{tabular}

\subsection{Analysis of design-of-use and design-in-use by traveler}

The point of the above combination of value creation models is obviously design-of-use and design-in-use by the customer. What actually happens when inbound tourists try to plan their itineraries? We assume that the key element to answer this question lies in the dynamics of customer expectations over time. Customer expectation and construal level theory

Studies on services (e.g., [13]) assert that customer expectations are important, as they embody the criteria applied in customers' evaluations of the services they receive. Customer expectations represent their recognition of whether a service meets their requirements. Based on these studies, this paper defines customer expectations as what customers emphasize about a product or service [14]. Besides, they may change over time; expectations during design-in-use may be different from those related to design-of-use due to changes in psychological distance and environment.

Psychological distance is referred to in the construal level theory [15] in the field of consumer behavior, which predicts that one's awareness of an object depends on the psychological distance between the person and that object. The psychological distance can be determined with certain distances, such as the physical distance, temporal distance, cultural distance, and degree of knowledge. We assume that this theory may be applied to differentiate design-in-use with design-of-use by customers, whose psychological distances vary much more than those of experts.

Results of the analysis

An analysis of the completed questionnaire survey and readings of the GPS logger mentioned earlier revealed the following:

- $54 \%$ of tourists planned less than half their itinerary in advance.

- $51 \%$ of tourists decided places they wished to visit in Tokyo in the morning of the very same day of their tours. Furthermore, they tend to show higher satisfaction than others.

These results imply that tourists do not fully plan in advance (i.e., design-of-use), and instead, they adapt their plans to suit the latest situation-in this case, mainly in the morning on the same day (i.e., design-in-use).

In addition, we asked tourists which tourism-related elements stood out in their mind at different stages, so as to know their 
expectations about traveling in Japan. Figure 4 summarizes its results. 15 tourism-related elements are grouped into the following categories: travel experiences, hospitality, travel services, transit, accommodation, food, and tourist attractions. The results concerning 'planning to visit Japan' and 'immediately before visiting Japan' would extract traveler's expectations in the design-of-use phase and that concerning 'during stay in Japan' would extract details about the design-in-use phase.

A detailed principal component analysis (PCA) reveals that at each step, the psychological distance element for which customer expectations change the most, is different for each dataset:

- Design-of-use depends on cultural distance defined by how many times a tourist has traveled in Japan.

- Design-in-use depends on spatial distance between Tokyo and the tourist's country of residence.

The differences between the elements of psychological distance elements for which customers' expectations change the most suggests that customers should be clustered with each index at each stage of their trip and that they should be supported by their cluster's features. In the preceding study, we presented prototype-based design for hot start in order to cope with 'the paradox of the active user'. Customers would benefit from predefined configurations of expectations and tour activities based on such clusters.

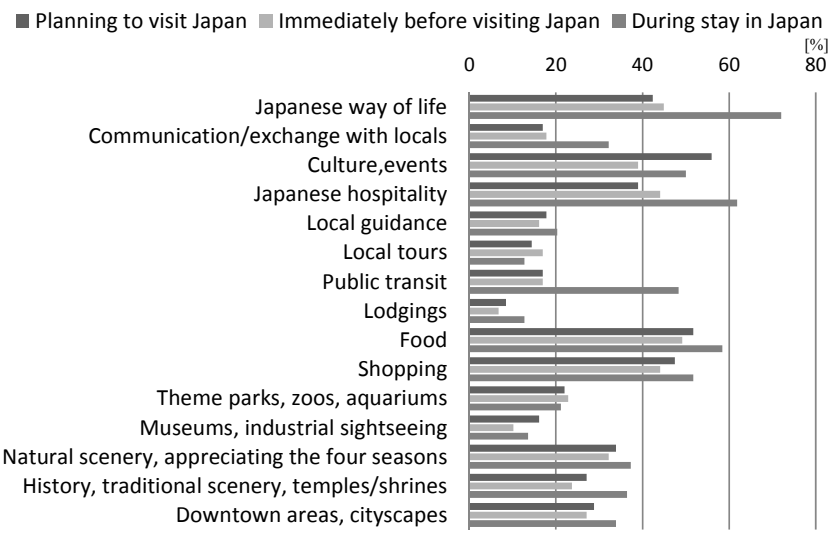

Figure 4 Important aspects for inbound tourists at different stage of their travel planning [14].

\subsection{Prospect of design-from-use}

In the research project, we utilized the retrieved use data as a new dependency among components. This enabled us adopt DSM techniques so that travel agencies can analyze and construct system architecture of sightseeing tour based on design-from-use.

A lot of community based web services have emerged these days such as TripAdvisor, EveryTrail, and Facebook so that FITs can share word-of-mouth and travel experiences with each other. From the viewpoint of the proposal presented in the section 3, however, support of design-of-use and design-in-use for travelers are insufficient. The interactive tour planning system we developed may work as a platform for its support. Furthermore, the planning system would be enhanced by connecting other web services concerning community based co-creation as listed above. Collaboration of the planning system and the survey method of tourist activities using GPS logger is also promising in measuring the difference between design-of-use and design-in-use.

\section{Discussion}

A common understanding of service is that service is recognized as processes, not physical dimension. Tour services analyzed in this paper are typical such service processes.
Sampson and Froehle presented Unified Service Theory to clearly delineate service processes from non-services (such as make-tostock products) [16]. They argued that feedback from customer side to manufacturing activities of provider is an essential characteristic of service processes, and it differentiates services from products. Furthermore, service processes such as individual tour have less predefined connections among components than that of product. It causes high freedom of connecting components and much emphasis on use phase. Thus, continuously sensing how customers combine and use components as presented in this paper would give us hints on servicification of products in manufacturing industry.

\section{Conclusion}

This paper presented a combination of different type of value creations that can bring design and use closer. Design-of-use (configuration) and design-in-use (adaptation) by the customer work as a bridge between value creations. Design-from-use, which is amplified by accumulated use data, contributes to value co-creation by both the manufacturer and the customer community. This kind of eco system, consisting of different stakeholders and different designs, is the key for sustainable value creation. Future research on the topic would include developing a concrete method of supporting design-in-use by the customer and applying the concept to the manufacturing industry.

\section{Acknowledgement}

This research is supported by Service Science, Solutions and Foundation Integrated Research Program (S3FIRE), Research Institute of Science and Technology for Society (RISTEX), Japan Science and Technology Agency (JST).

\section{References}

[1] Tomiyama, T., et al, (2009), Design methodologies: Industrial and educational applications, CIRP Annals - Manufacturing Technology, 58/2: 543-565.

[2] Redstrom, J., (2006), Towards user design? On the shift from object to user as the subject of design, Design Studies, 27/2:123-139.

[3] Duttrich, Y., Eriksén, S., Hansson, C., (2002), PD in the wild; evolving pracitves of design in use, In PDC 02 Proceedings of the Participatory Design Conference, T. Binder, J. Gregory, I. Wager (Eds.): 124-133.

[4] Meier, H., Roy, R., Seliger, G., (2010), Industrial Product-Service Systems-IPS2 CIRP Annals - Manufacturing Technology, 59/2:607-627.

[5] Hara, T., et al, (2009), Service CAD System to Integrate Product Behavior and Service Activity for Total Value, In CIRP Journal of Manufacturing Science \& Technology, CIRP, 1/4:262-271.

[6] Hara, T., Arai, T., (2012), Encourage non-designer's design: sustainable value creation in manufacturing products and services, CIRP Annals - Manufacturing Technology, 60/1: 171-174.

[7] Tseng, M.M., Du, X., (1997), Design by customers for mass customization products, CIRP Annals - Manufacturing Technology, 47/1:103-106.

[8] Ueda, K., et al, (2009), Value Creation and Decision-making in Collaborative Society, CIRP Annals - Manufacturing Technology, 58/2:681-700.

[9] Henderson, A., and Kyng, M., (1991), There's no place like home: continuing design in use, In Design At Work: Cooperative Design of Computer Systems, J. Greenbaum and M. Kyng, Eds. L. Erlbaum Associates, Hillsdale, NJ:219-240.

[10] Botero, A., Kommonen, K.-H., and Marttila, S., (2010), Expanding design space: Design-in-use activities and strategies, In Proceedings of the DRS Conference on Design and Complexity.

[11] Tseng, M.M., Jiao, X.J., (1996), Design for mass customization, CIRP Annals Manufacturing Technology, 45/1:153-156.

[12] Oizumi, K. et al, (2012), Supporting System for Tour Lineup Design based on Tour Service Modeling, In Proceedings of CIRP IPS 2 Conference 2012, CIRP 143-148.

[13] Zeithaml, V. A., Berry, L. L., and Parasuraman, A., (1993), The nature and determinants of customer expectations of service, Journal of the Academy of Marketing Science, 21, 1, 1-12.

[14] Shimada, S., Ota, J., and Hara, T., (2012), Analyzing customers expectation on service for encouraging participatory design, In Proceedings of CIRP IPS 2 Conference 2012, CIRP: 257-262.

[15] Trope, Y., and Liberman, N., (2003), Temporal Construal, Psychological Review, 110/3: 403-421.

[16] Sampson, S., and Froehle, C., (2006), Foundations and Implications of a Proposed Unified Services Theory, Production and Operations Management, 15/2: 329-343. 